Final Report:

High-R Window Technology Development - Phase IIB.

\title{
Monitored Thermal Performance Results of Second Generation Superwindows in Three Montana Residences
}

\author{
Dariush Arasteh \\ Windows and Daylighting Group \\ Lawrence Berkeley Laboratory \\ Berkeley, CA 94720
}

\author{
Submitted to: \\ Mark Jackson \\ Residential Technology Section \\ Bonneville Power Administration \\ Portland, OR
}

May 1993

\section{DISCLAIMER}

This report was prepared as an account of work sponsored by an agency of the United States Government. Neither the United States Government nor any agency thereof, nor any of their employees, makes any warranty, express or implied, or assumes any legal liability or responsibility for the accuracy, completeness, or usefulness of any information, apparatus, product, or process disclosed, or represents that its use would not infringe privately owned rights. Reference herein to any specific commercial product, process, or service by trade name, trademark, manufacturer, or otherwise does not necessarily constitute or imply its endorsement, recommendation, or favoring by the United States Government or any agency thereof. The views and opinions of authors expressed herein do not necessarily state or reflect those of the Ünited Stutes Government or any agency thiêieứ. 


\title{
Monitored Thermal Performance Results of Second Generation Superwindows in Three Montana Residences
}

\author{
Dariush Arasteh \\ Windows and Daylighting Group \\ Lawrence Berkeley Laboratory \\ Berkeley, CA 94720
}

\section{Executive Summary}

Simulation studies have shown that highly insulating windows with moderate solar transmittances ( $R$ values greater than $6 \mathrm{hr}-\mathrm{ft}^{2}-\mathrm{F} / \mathrm{Btu}$ and shading coefficients greater than 0.5 ) can outperform insulated walls on any orientation, even in a northern U.S. climate. Such superwindows achieve this feat by admitting more useful solar heat gains during the heating season than energy lost through conduction, convection and infrared radiation.

Testing of first generation superwindows in three new homes in northern Montana during the winter of 1989-1990, reported in an earlier study, indicated that the glazed areas of superwindows can in fact outperform insulated walls on obstructed off-south orientations. However, this same study also showed that further improvements in the thermal performance of window edges and frames are necessary if the entire window is to outperform an insulated wall. As a result, second generation superwindows with improved frame, edge, and glazing features were installed in these houses during the summer and fall of 1990 and these windows were monitored during the winter of 1990-1991. Results from this monitoring effort, discussed in this paper, showed that while snıall performance improvements may have been made with these second generation superwindows, the frame and edge still limited performance.

\section{Introduction and Background}

Of all residential building envelope elements, windows have typically had the highest heat loss rates. The rapid commercialization of low-emissivity coatings and low-conductivity gas-filling has begun to upgrade window performance in moderate and cold climates. Windows with $\mathrm{R}$-values better than those of the best doubleglazed low-emissivity, gas-filled window can provide added energy benefits in heating dominated climates. Simulation studies (Sullivan and Selkowitz 1985 ) have shown that even north-facing windows with $R$-values greater than $6 \mathrm{hr}-\mathrm{ft}^{2}-\mathrm{F} / \mathrm{Btu}$ and shading coefficients greater than 0.5 (i.e. at least half the solar heat gain of clear single glazing) will provide more useful solar heat gain than conductive losses in a typical residence in a northern climate. Such "superwindows" thereby outperform the best insulated walls. Other advantages of superwindows include significantly higher winter interior glazing surface temperatures which result in more comfortable spaces and reduced occurrences of condensation and the design freedom to use more and larger windows on all orientations. 
Recent research has focused on the development of R6- R10 superwindows using three glazing layers, two low-emissivity coatings, and a low-conductivity gas-fill. Previous studies have detailed the design configurations for such superwindows (Arasteh, Selkowitz, and Hartmann 1985) and have proven, through laboratory measurements, that the measured center-of-glass performance for such windows matches predictions (Arasteh, Selkowitz, and Wolfe, 1989). As a follow-up to these laboratory measurements, three different superwindow prototypes were designed and manufactured in conjunction with three major national window manufacturers (Arasteh and Selkowitz, 1989). Each manufacturer's prototype was an adaptation of the superwindow principles (three layers, one low-emissivity coating per gap, and the use of low-conductivity gas fills) to their existing glazing and sash constraints. Each of these first-generation superwindow prototypes was installed in a Bonneville Power Administration (BPA) Residential Construction Demonstration Project (RCDP) test house in north-west Montana (Arasteh, 1991). Each house also contained one control window, typically a double glazed low-emissivity window, representative of typical state-of-the-art products. The one control window and an adjacent superwindow in each house were monitored during the winter of 1989 1990.

The results of this monitoring effort showed that:

1) Field measured center-of-glass U-values agreed extremely well with those predicted by WINDOW 3.1. WINDOW can therefore continue to be used with confidence for the design and center-of-glass evaluation of future superwindow prototypes.

2) The glazed areas of superwindows can be net annual energy gainers (thus outperforming an insulated wall), even on obstructed off-south orientations in a climate as severe as northern Montana. Super glazings greatly out-performed low-e double glazed control windows.

3) Thermal bridging resulting from the use of conductive spacers and the added heat loss from high conductivity window frames considerably degraded the thermal performance of superwindows. Increasing the thermal performance of frames and edges is mandatory for the next generation of superwindows.

As a result of these conclusions, BPA and LBL decided to work with the individual manufacturers involved to try and produce a new round of superwindows with improved overall total window (frame, sash, and glass) performance. New "second generation" prototypes were produced, installed, and monitored during the next winter (1990-1991). The objectives were to produce prototypes more suitable for mass-production with lower total window U-values and higher total window shading coefficients.

\section{Descriptions of Second Generation Prototypes}

Because of the short time frame involved (there was less than six months to alter the windows and have them ready for monitoring), the second generation superwindows could not be significantly different from the first generation superwindows. The control windows remained the same. Alterations were thus limited to sash replacements. The windows are summarized in Table 1. 
The second generation superwindow in Site 215 is an improvement over the previous year's prototype in that it no longer uses a thin vinyl strip over the spacer to reduce edge heat loss. An insulatin $z$ spacer was developed and used in the second year's prototype. The primary effect of this change is to maintain edge performance at a level better than that of a conventional aluminum spacer system and to be able to do this without decreasing the glazing area; thus heat losses are about the same yet solar gains increase. The previous year's superwindow used Krypton as a gas-fill while the second year's prototype used much cheaper Argon and a slightly wider gap; this resulted in a small performance drop but was viewed as a much more costeffective possible product offering.

The second generation superwindow in Site 217 is an improvement over the previous year's in that the insulating glass unit was replaced with a lower U-value unit with an insulating edge design. Instead of using a double coated low-e polyester film (which turned out to be difficult to manufacture and handle), two separate suspended low-e films are used. These films are separated at the edge by an insulating foam spacer, thereby creating a third gas gap as well as an insulating edge. The sash used with this window limited IG widths to $3 / 4^{\prime \prime}$ and thus the lowest achievable center-of-glass $U$-value was 0.15 . This product is now produced commercially with in a 1 " wide IG unit with a center-of-glass U-value of 0.12 .

Finally, the second generation superwindow in Site 219 is an improvement over the previous year's in that the inner most glazing layer (a snap in storm panel) was replaced with a panel of similar emittance but with a much higher solar transmittance. Thus, in this case, conductive losses remain the same yet total window solar heat gain properties will rise.

Table 2 lists the total window U-values and total window Solar heat gain coefficients (SHGCs) for each site's control windows, the first generation superwindows, and the second generation superwindows. Figure 1 shows winter temperatures typical of all three sites. Figure 2 shows fish-eye photos through each of the three sites; these are shown to give the reader an idea of the obstructions in front of the windows.

\section{Use of Infrared Thermography to Refine Prototype Designs}

Because some of the changes suggeste $d$ for these second generation superwindow prototypes effect a limited area of the window (i.e. the sash and edge-of-glass), a laboratory based infrared thermography facility was used to examine the performance of existing components and the same components with proposed design and/or material changes. Arasteh et.al., 1992, provides a complete discussion on this process.

Because some of these designs were proprietary, they cannot be discussed in this report. Infrared thermography analyses on these and other windows continues in order to help manufacturers design more efficient edges and frames.

\section{Discussion of Monitored Results}

The monitoring of the three second generation superwindows and three control windows followed the same procedure used as part of the earlier study (Arasteh, 1991) and is therefore not repeated here. Unfortunately, monitoring of these 
windows could not begin until late in November and we thus cannot comment on annual heating season energy flows.

The monitoring arrangement is discussed in Arasteh, 1991 and illustrated in Figure 3. In each house, a control (low-e gas filled or equivalent) window is positioned immediately next to the monitored superwindow. Each window is monitored with a heat-flux meter in the center-of-the-glass and with four thermistors in the following locations:

Thermistor \#1: Center-of-glass

Thermistor \#2; 2.5 " in from the sightline

Thermistor \#3: At the sightline

Thermistor \#4: On the sash.

It is instructive to compare monitored center-of-glass U-values (based on the center of glass heat flux, indoor temperature, glass surface temperature, exterior temperature) and calculated center-of-glass U-values. These values are shown in Table 2. Generally, the agreement is very good. In some cases the measured superwindow U-values are a little lower than calculated; explanation for this include the possible filling of the superwindow in Site 215 with Krypton instead of Argon, uncertainties in interior and exterior temperatures, and uncertainties in exterior film coefficients. At Site 217, the control window's measured U-value was higher than its simulated $U$-value; this could easily be explained by a gas leak. However, it is important to note that the differences between measured and calculated U-values are small in absolute terms and that the relative differences between control windows and superwindows is similar for the calculated and the measured numbers.

The U-value of the total installed window assembly cannot be measured to any reasonable degree of accuracy in the field. Calculated total window U-values, determined per NFRC 100-91 and presented in Table 2 are much higher than center-of-glass $U$-values. This is not surprising since there were no major changes to the construction of the frame and sash in any of the three designs.

We are also interested in the annual performance of the center-of-glass and the total window. Unfortunately, due to the short amount of time available in 1990 to produce and install the new superwindows, monitoring could not start until late November 1990. Thus, the months of September and October are omitted from this discussion. Figure 4 shows the "yearly" (i.e. December-May) heating season energy flux for the center-of-glass and total control windows and superwindows and for typical R-11 and R-19 walls at all three sites. The center-of-glass superwindow performance is typically equivalent to that of the walls while the total superwindow performance is noticeably worse than the walls. This is in contrast to the previous year's performance (September - May) where the superwindow's performance was significantly higher when compared against the walls. This is not surprising, given that there is no data from September and October. What this implies, which is shown in Figure 5 for Site 219, is that for this climate, during the fall and the spring, superwindows can outperform walls, whereas in the middle of the winter the temperature differences are too great and the solar radiation levels are too low for the superwindows to outperform an insulated wall.

The overall trends seen in the yearly heating season energy flux for 1990-1991 are similar to those seen in the previous year. Performance seems to be most significantly a function of solar exposure. Site 219's superwindows were a little less obstructed than Site 215's superwindows, which also faced west, and thus performed 
slightly better. Site 217 faced west but was heavily shaded by an overhang (see Figure 2) and its performance reflects this.

Glazing and sash surfaces temperatures were analyzed for the 1990-1991 season as they were during the previous year. Examples of these plots are shown in Figure 6. By normalizing all temperature differences to the center-of-glass to outdoor temperature difference, we eliminate much of the scatter in these plots. In addition, we reference all temperature differences to the best insulating element of the window. We see, as we did from the $1989-90$ data, that in general $\mathrm{T} 2$ is almost as high as $\mathrm{T} 1$; this tells us that the 2.5 " rule for edge-of-glass effects is reasonable, but not perfect for superwindows.

At site 215, the changes to the window reflected in the 1990-91 data did not make any significant changes to the Thermistor temperature differences presented in Arasteh, 1991; this is an accomplishment since the same performance was achieved by dropping the vinyl insulating strip and in just using a newly developed spacer.

Because Site 217 was not heated in 1989-90, interior air and surface temperatures fluctuated significantly; $1989-90$ data for this site was therefore not analyzed.

However, this problem was corrected in 1990 and we can therefore look at 1990-91 control window and superwindow data. With the control window, sash temperatures (T4) are higher than sightline temperature; not surprising since a metal spacer system is used. With the superwindow, this trend is reversed, showing the effectiveness of the insulating edge.

With site 219, the temperature pattein is similar in 1990-91 as it was in 1989-90. This is to be expected since there were no changes to the edge system.

\section{Conclusions}

As with the previous year's results, total window performance, also estimated using a combination of measured data and simulation tools, was not as good as center-ofglass performance. This is no surprise given that the insulating value of the frame and edge materials is not as high as that of the glazing system and that there are no solar gains through the frames.

Thermistor data from the edges of windows at Sites 215 and 217 indicated that the new edge systems in these designs made a noticeable difference in sightline temperatures and thus heat transfer rates. This improvement should virtually eliminate any condensation on the glazings. Although not measured in the field directly, the solar heat gain coefficients from the new superwindows at Sites 215 and 219 increased.

Comparing the three sites to one another it is evident that even though they could all be classified as obstructed to some degree, the amount of obstructions did make a noticeable difference on the total glazing flux. In other words, the site should be considered in addition to the orientation. A north facing window with no obstructions may be better than a west facing window with heavy obstructions. Designers should note site characteristics and place windows accordingly.

While small improvements were noted by the second generation superwindows over the first generation superwindows, the differences were not large enough to 
substantially change the conclusions from the previous study. Advances in frame and edge technology are still necessary if windows are to be designed to serve as net energy gainers in such climates. Note also that if a window is just barely a net energy gainer over the course of a heating season, it will probably be a net energy looser during the coldest portions of the heating season. (The use of insulating night shades with superwindows is therefore still beneficial.) Conversely, if a window is to be a net energy gainer on a daily basis for the cold months of the year, it will end up being a significant gainer during the fall and spring months. Future studies should better identify what targets utilities are looking for and what windows will be needed to meet these targets. Future studies should also address the energy impacts of the framing around a window and explore options to reduce this source of window related heat loss.

This report is the culmination of a five year effort to develop and monitor superwindow prototypes. It has led to the successful commercialization of superglazing technologies and has helped foster an interest in the industry in the development of insulating edge and frame designs. Demonstration and monitoring projects have served a useful role in transferring research concepts to the marketplace.

\section{Acknowledgements}

The author wishes to thank Jonathan Slack and Fred Beck of LBL for their tremendous help in analyzing the data from this project. Invaluable logistical help on the monitoring side of this project was provided by Johnny Douglass and Jim Maunder of the Washington State Energy Office; Dave Eyes, Brad Hesse, Kurt Schultz, and Doug Cote of W.S. Flemming and Associates. Materials and time donated by Andersen Corporation, Cardinal IG, Owens-Corning Fiberglass, Rolscreen Company, and Southwall Technologies were essential to the completion of this project.

This work was supported by the Residential Technology Section of the Bonneville Power Administration under Contract No. DE-AI79-86BP63401. Additional support was provided by the Assistant Secretary for Conservation and Renewable Energy, Office of Building Technologies, Buildings Systems and Materials Division of the U.S. Department of Energy under Contract No. DE-AC03-76SF00098.

\section{References}

Arasteh, D., Selkowitz, S., and Hartmann, J. "Detailed Thermal Performance Data on Conventional and Highly Insulating Window Systems. "Proceedings of the ASHRAE/DOE/BTECC Conference on Thermal Performance of the Exterior Envelopes of Buildings III, Clearwater Beach, FL. December 1985. ASHRAE, Atlanta GA.

Arasteh, D, and Selkowitz, S. "A Superwindow Field Demonstration Program in Northwest Montana." Proceedings of the ASHRAE/DOE/BTECC/CIBSE Conference on Thermal Performance of the Exterior Envelopes of Buildings IV, Orlando, FL. December 1989. ASHRAE, Atlanta GA. 
Arasteh, D.; Selkovritz, S., and Wolfe, J. 1989. "The Design and Testing of a Highly Insulating Glazing System for use with Conventional Glazing Systems." Journal of Solar Energy Engineering, Transactions of the ASME, Vol. 111. February.

Arasteh, D., Beck, F., Griffith, B., Acevedo-Ruiz, and Byars, N. "Using Infrared Thermography for the Study of Heat Transfer Through Building Envelope Components." ASHRAE Transactions, Vol. 98, Part 1.

Arasteh, D. High-R Window Technology Development - Phase II: Final Report. Submitted to Bonneville Power Administration Report, December 1991.

Lawrence Berkeley Laboratory, 1992. "WINDOW 4.0: A PC program for analyzing window thermal performance." LBL-32091, March. Berkeley, CA.

Sullivan, R. and Selkowitz, S. 1985. "Window Performance Analysis in a SingleFamily Residence," in Proceedings of the ASHRAE/DOE/BTECC Thermal Performance of the Exterior Envelopes of Buildings III Conference, December. ASHRAE, Atlanta GA. 
Table 1: Summary of Site and Window Characteristics

\begin{tabular}{|c|c|c|c|}
\hline & Site 215 & Site 217 & Site 219 \\
\hline Location & Libby, MT & $\begin{array}{l}\text { Frenchtown, } \\
\text { MT }\end{array}$ & $\begin{array}{l}\text { Kalispell, } \\
\text { MT }\end{array}$ \\
\hline Orientation & West & West & West \\
\hline $\begin{array}{l}\text { Site } \\
\text { Characteristics }\end{array}$ & $\begin{array}{l}\text { obstructed } \\
\text { by hills \& } \\
\text { trees }\end{array}$ & $\begin{array}{l}\text { completely } \\
\text { obstructed } \\
\text { by deck } \\
\text { overhead }\end{array}$ & $\begin{array}{l}\text { partially } \\
\text { obstructed } \\
\text { by trees }\end{array}$ \\
\hline Operator Type & Casement & Casement & Casement \\
\hline Frame Type & $\begin{array}{l}\text { Wood, } \\
\text { vinyl clad }\end{array}$ & Fiberglass & $\begin{array}{l}\text { Wood, } \\
\text { alum clad }\end{array}$ \\
\hline $\begin{array}{l}\text { Spacer Type } \\
\text { (Control Window) }\end{array}$ & Aluminum & Aluminum & Wood \\
\hline $\begin{array}{l}\text { Spacer Type } \\
\text { (Superwindow) }\end{array}$ & $\begin{array}{l}\text { Insulated; } \\
\text { (proprietary) }\end{array}$ & $\begin{array}{l}\text { Aluminum } \\
\text { with complete } \\
\text { foam break }\end{array}$ & $\begin{array}{l}\text { Wood, and } \\
\text { Aluminum }\end{array}$ \\
\hline $\begin{array}{l}\text { Glazing } \\
\text { Assembly } \\
\text { (Control Window) }\end{array}$ & $\begin{array}{l}\text { Double } \\
\text { Glazing with } \\
\text { Low-E, Ar }\end{array}$ & $\begin{array}{l}\text { Double } \\
\text { Glazing with } \\
\text { double coated } \\
\text { suspended, } \\
\text { Low-E film } \\
80 / 20 \mathrm{Kr} / \text { air }\end{array}$ & $\begin{array}{l}\text { Double } \\
\text { Glazing } \\
\text { with Low-E } \\
\text { air }\end{array}$ \\
\hline $\begin{array}{l}\text { IG Width } \\
\text { (Control Window) }\end{array}$ & $0.75^{\prime \prime}$ & $0.75^{\prime \prime}$ & $1.125^{\prime \prime}$ \\
\hline $\begin{array}{l}\text { Glazing } \\
\text { Assembly } \\
\text { (Superwindow) }\end{array}$ & $\begin{array}{l}\text { Triple } \\
\text { Glazing with } \\
2 \text { Low-E, Ar }\end{array}$ & $\begin{array}{l}\text { Double } \\
\text { Glazing with } \\
\text { two suspended } \\
\text { Low-E films } \\
90 / 10 \mathrm{Kr} / \text { air, }\end{array}$ & $\begin{array}{l}\text { Triple } \\
\text { Glazing } \\
\text { with 2 } \\
\text { Low-E; one } \\
\text { Kr, one } \\
\text { air }\end{array}$ \\
\hline $\begin{array}{l}\text { IG Width } \\
\text { (Superwindow) }\end{array}$ & $1.2^{\prime \prime}$ & $0.75^{\prime \prime}$ & $1.56 "$ \\
\hline
\end{tabular}


Table 2:

Summary of Control Window and Superwindow Thermal Properties 1 for Control Windows, 1989-90 Superwindows (Superwdw1) and 1990-91 Superwindows (Superwdw2)

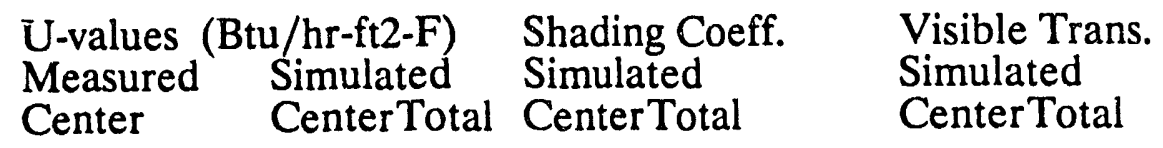

Site 215

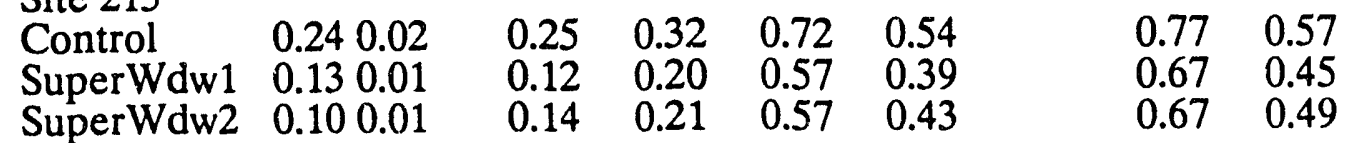

Site 217

\begin{tabular}{|c|c|c|c|c|c|}
\hline $\begin{array}{lll}\text { Control(90-91) } & 0.23 & 0.01 \\
\text { SuperWdw1 } & 0.18 & 0.02\end{array}$ & $\begin{array}{l}0.17 \\
0.18\end{array}$ & $\begin{array}{l}0.26 \\
0.26\end{array}$ & $\begin{array}{l}0.66 \\
0.62\end{array}$ & & $\begin{array}{l}0.71 \\
0.67\end{array}$ \\
\hline
\end{tabular}

Site 219

\begin{tabular}{|c|c|c|c|c|c|c|}
\hline $\begin{array}{l}\text { Control } \\
\text { Superwdw1 }\end{array}$ & $\begin{array}{l}0.370 .04 \\
0.170 .03\end{array}$ & $\begin{array}{l}0.35 \\
0.17\end{array}$ & $\begin{array}{l}0.45 \\
0.30\end{array}$ & $\begin{array}{l}0.86 \\
0.67\end{array}$ & $\begin{array}{l}0.59 \\
0.46\end{array}$ & $\begin{array}{l}0.77 \\
0.67\end{array}$ \\
\hline & 0.160 .02 & 0.17 & 0.30 & 0.70 & 0.49 & 0.62 \\
\hline
\end{tabular}

${ }^{1}$ U-values, Shading Coefficients, and Visible Transmittances calculated with WINDOW 4.0/FRAME 3.0 per NFRC procedures and based on 2'x4' overall sizes. 


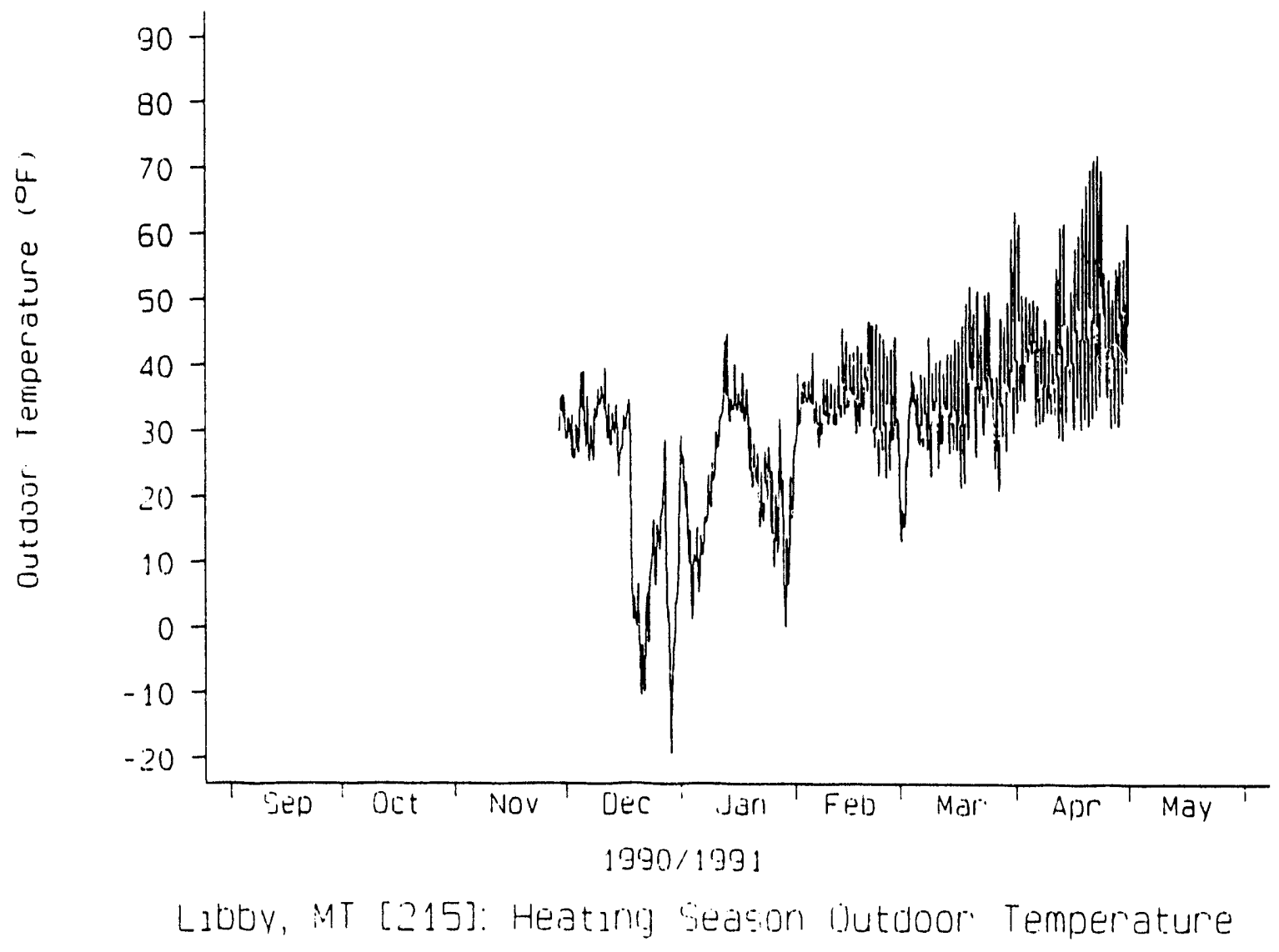

Figure 1: Outdoor temperatures for the 1990-91 heating season for Libby, MT and typical for all three sites. 


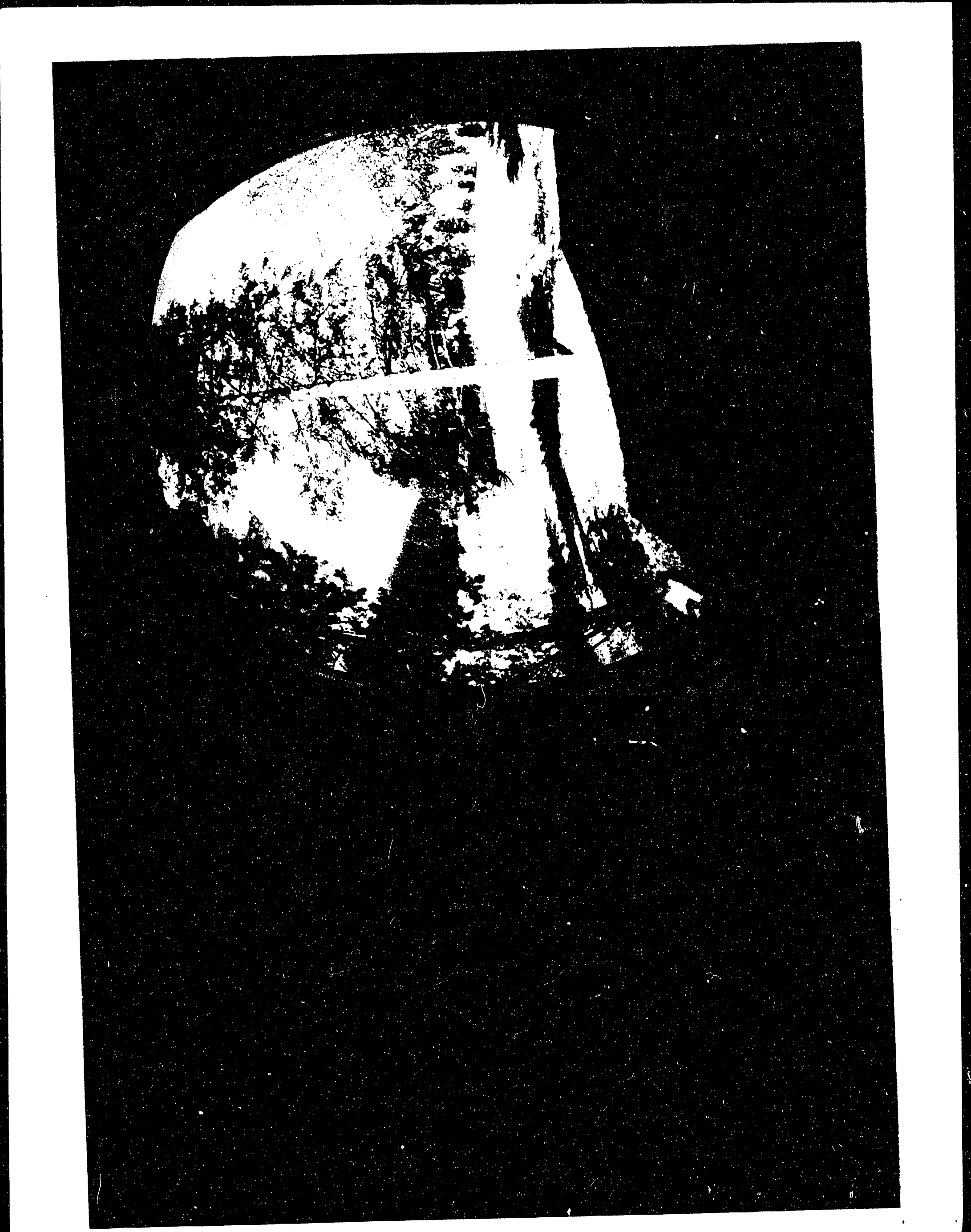




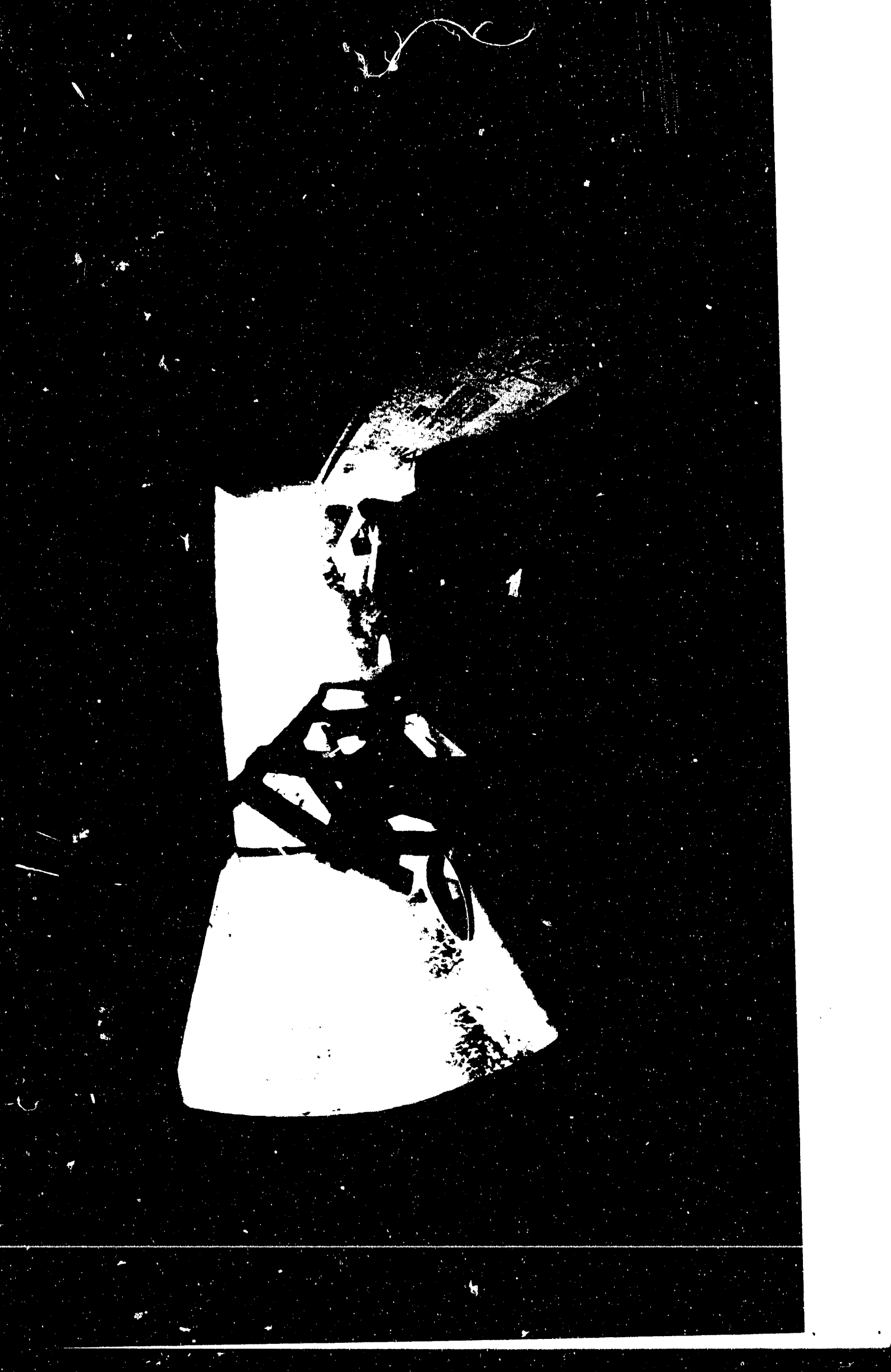




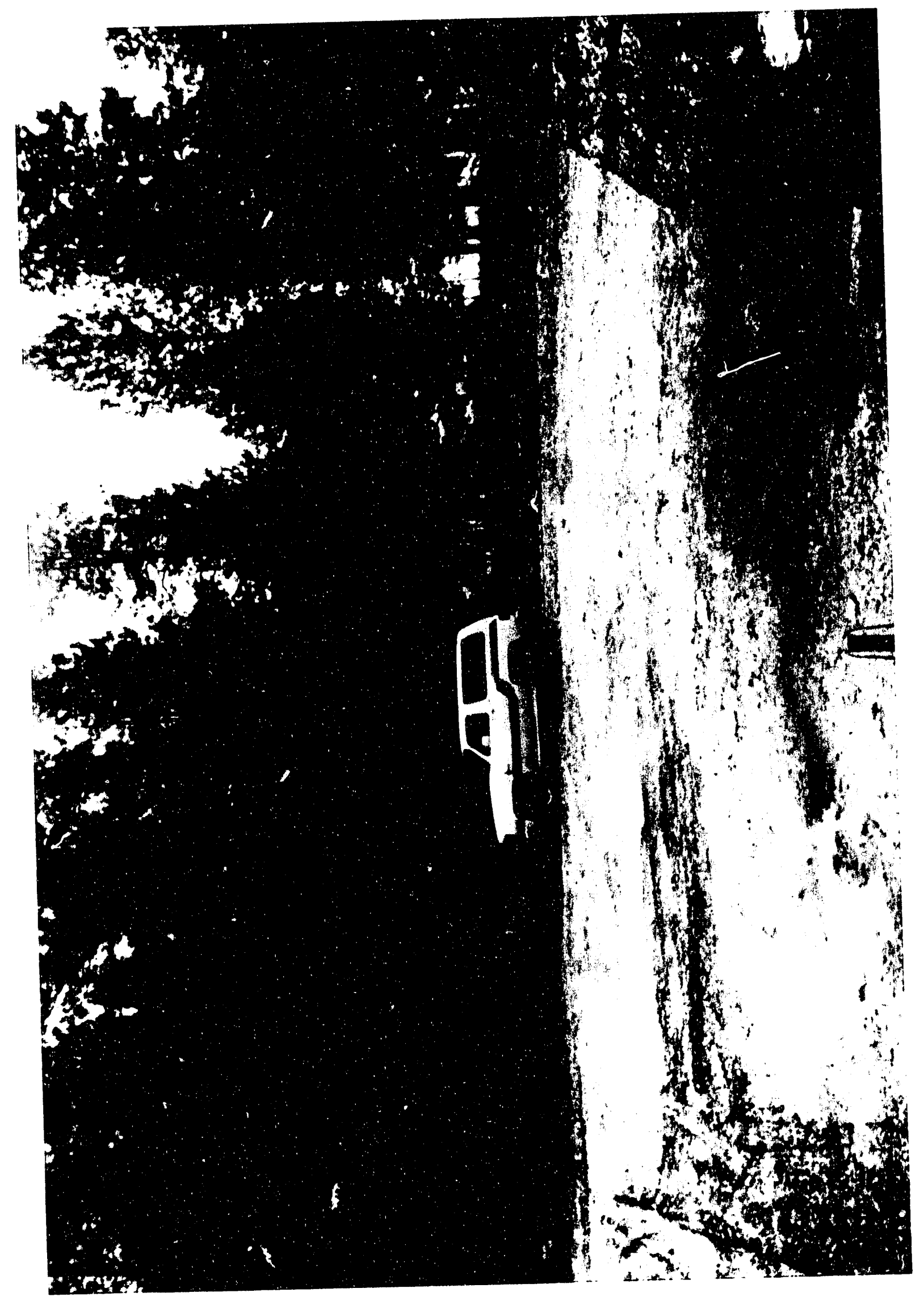


Figure 2a: View through monitored windows at Site 215.

Figure 2b: View through monitored windows at Site 217.

Figure 2c: View through monitored windows at Site 219. 


\section{Control Window}

\section{Supenwindow}

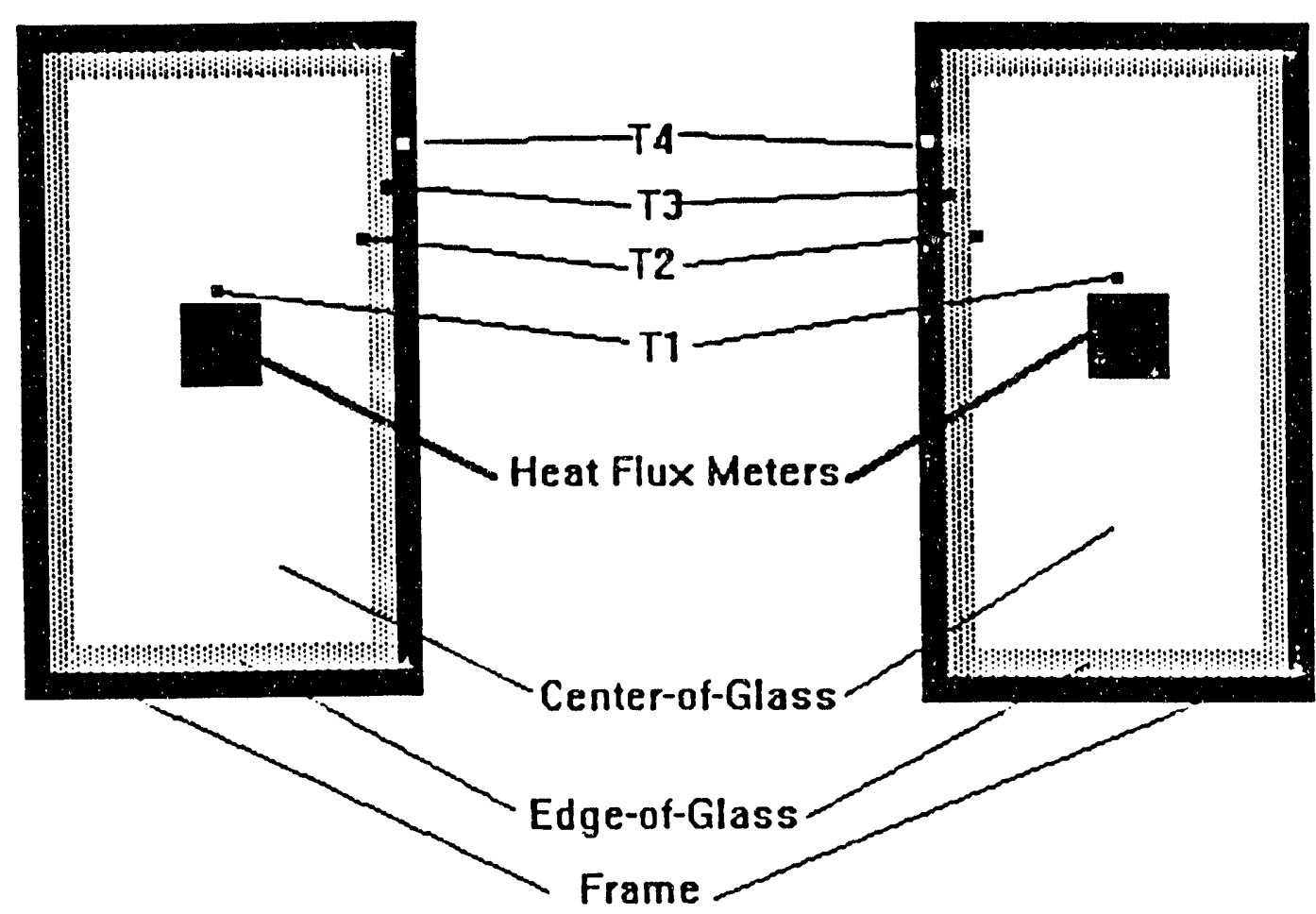

Figure 3: Side-by-side monitoring setup of control windows and superwindows and component window areas. 


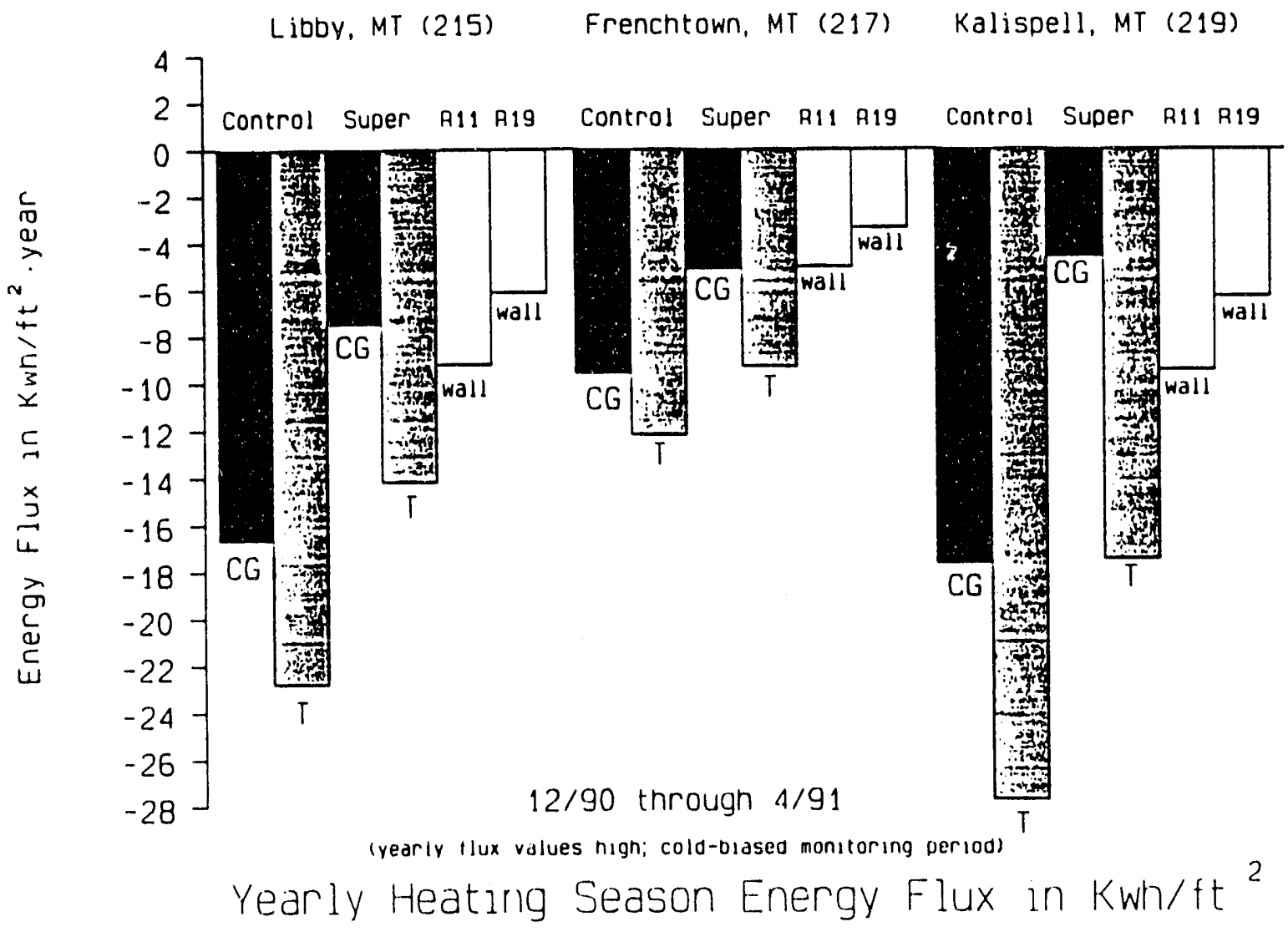

Figure 4: Yearly heating season energy flux for the center-of-glass areas of the control windows and superwindows, for the total area (center, edge, and frame) of the control windows and the superwindows, and for R11 and R19 walls. Center-ofglass heat fluxes are measured; other fluxes are based on calculations and real time data. 
Control Window (thin trace) Superwindow (thick trace)

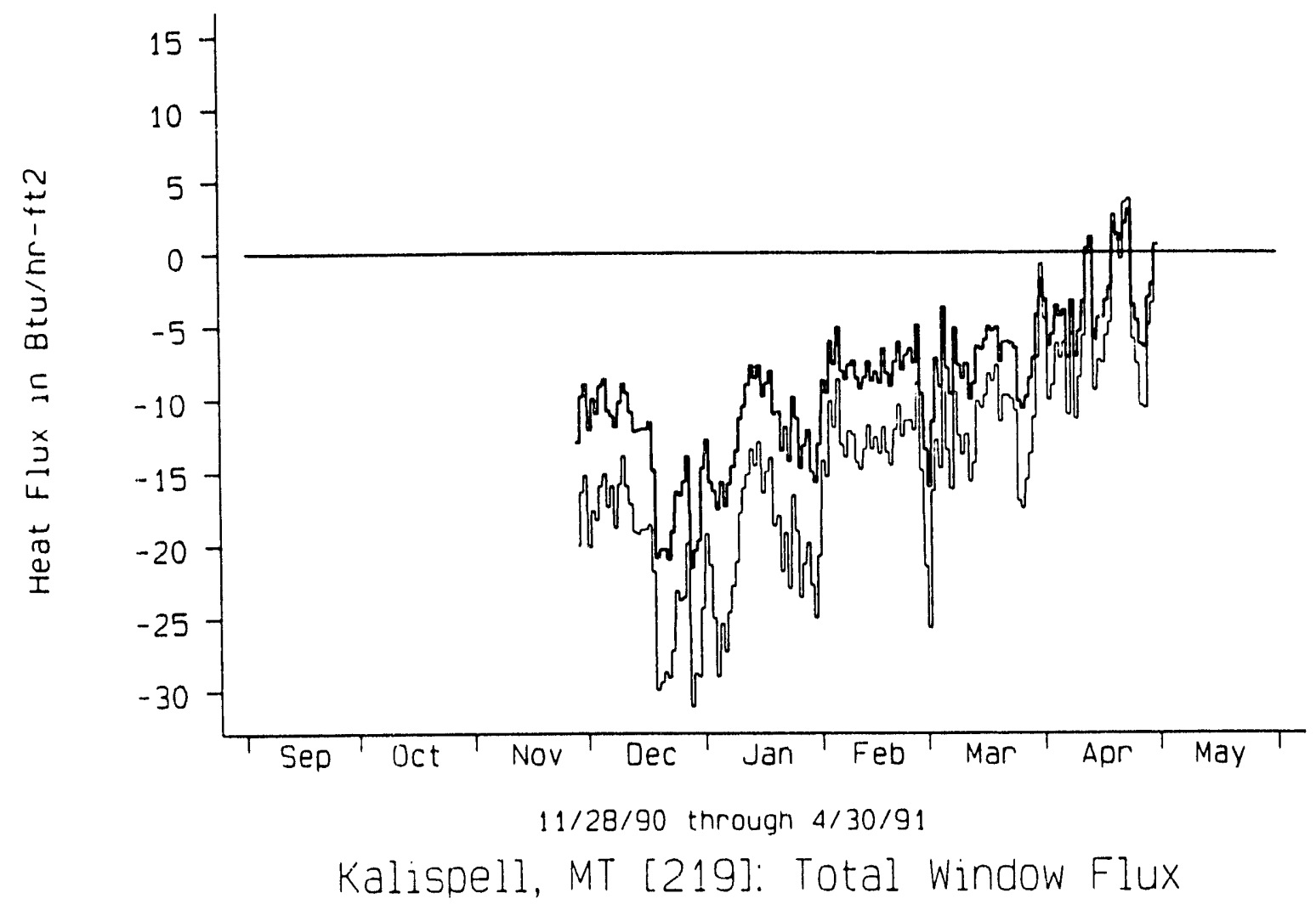

Figure 5: Hourly (daily average) total window heat fluxes for the control window and superwindow at Site 217. 


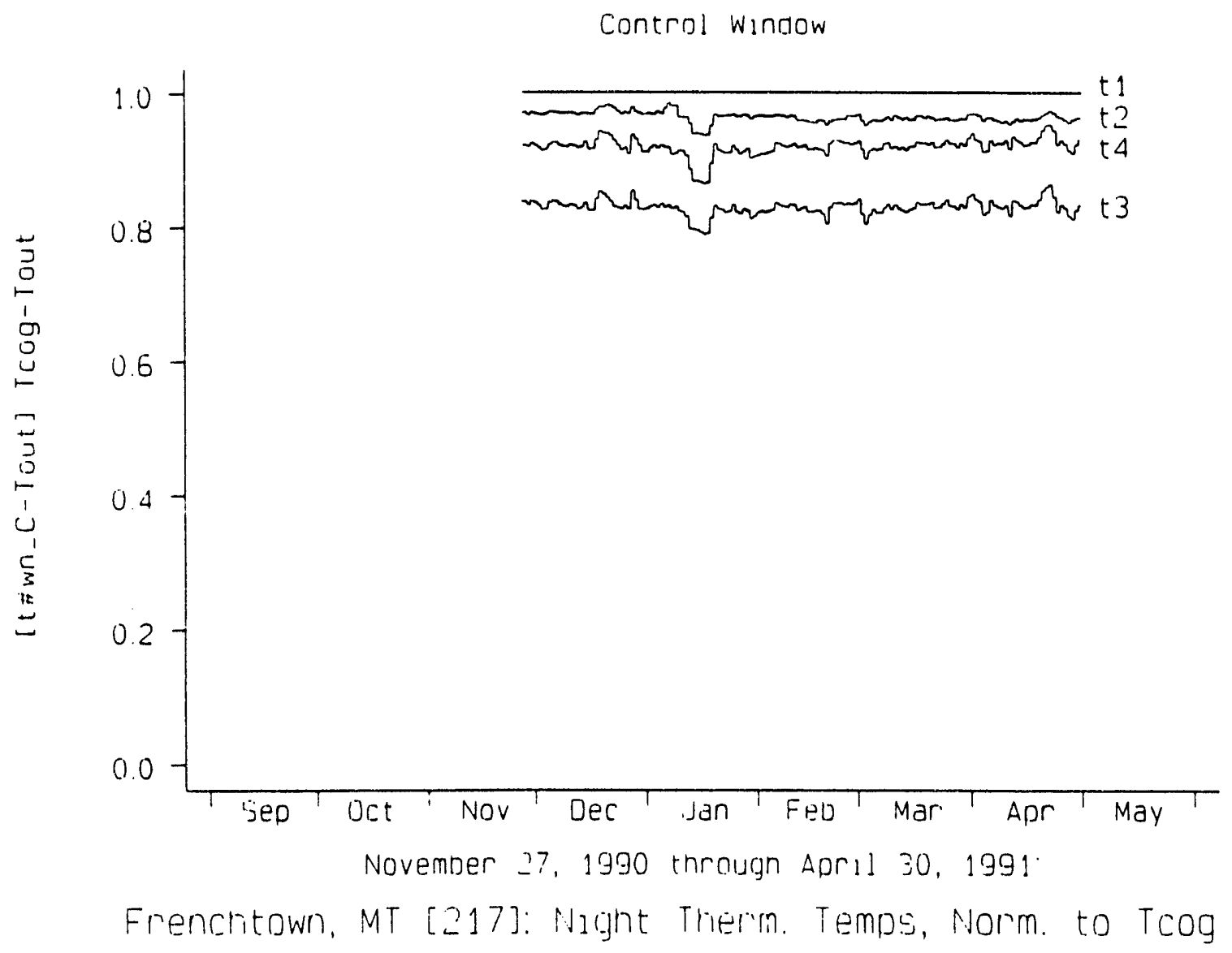

Figure 6a: Normalized nightime warm side surface temperatures for the control window at Site 217. 


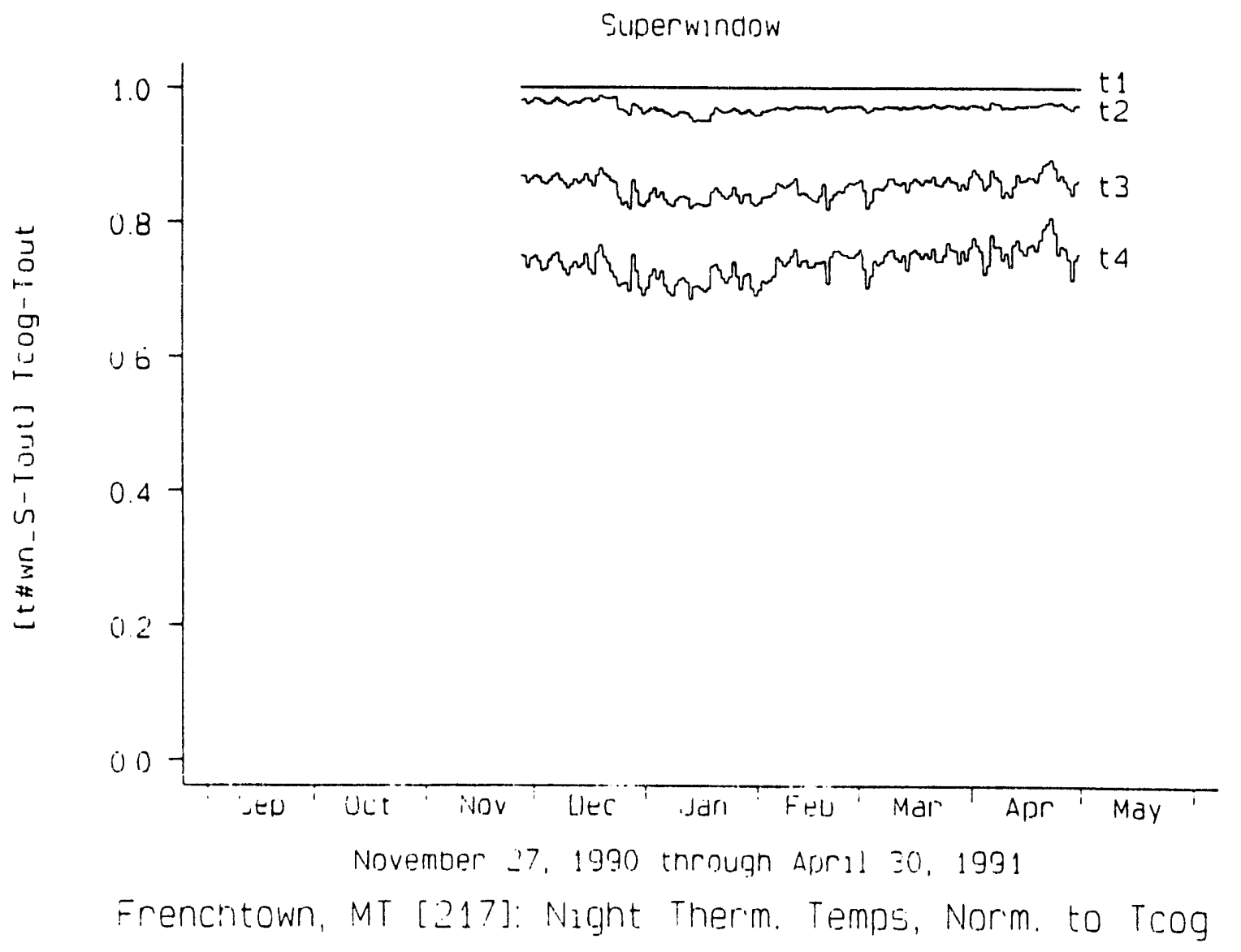

Figure 6b: Normalized nightime warm side surface temperatures for the superwindow at Site 217. 

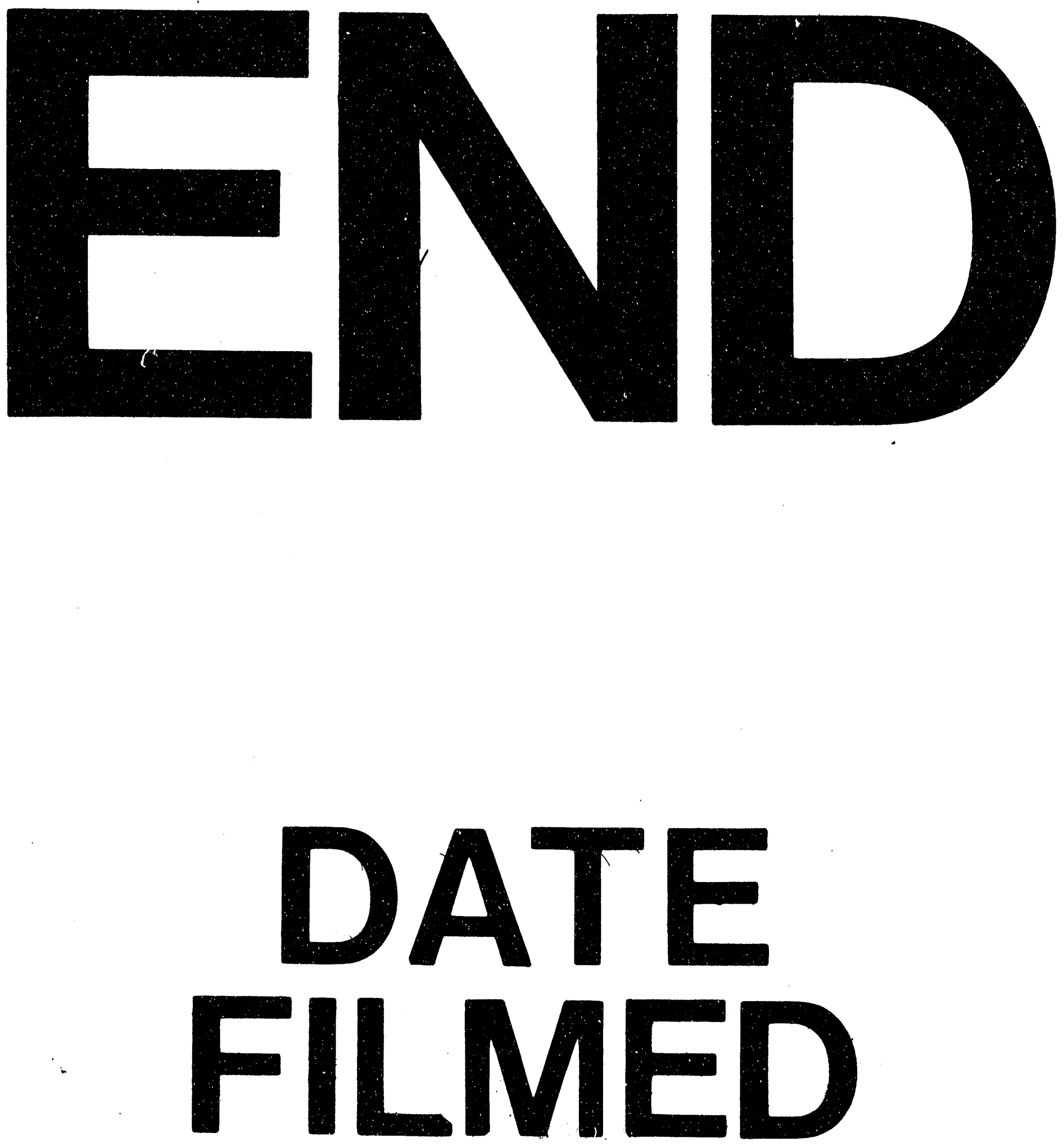

1

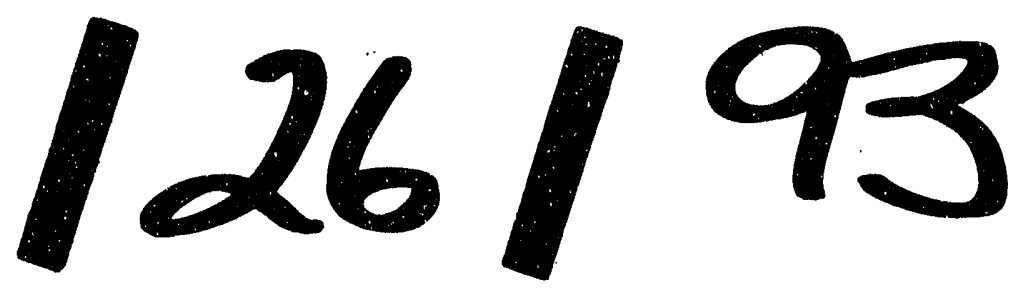


